\title{
ANALISIS FAKTOR PENUNJANG PENGOPTIMALAN KINERJA TERMINAL KABUPATEN KAPUAS
}

\author{
Andrianto Setiawan ${ }^{1}$ \\ ${ }^{1}$ Pemerintah Kabupaten Kapuas
}

\begin{abstract}
ABSTRAK
Kinerja terminal yang telah dibangun oleh pemerintah Kabupaten Kapuas masih belum optimal. Oleh sebab itu, dirasa perlu untuk melakukan penelitian guna mengidentifikasi, menyusun hirarki, menganalisa indikator pengaruh yang memiliki bobot yang siginifikan dalam mempengaruhi kinerja terminal serta mengetahui lokasi terminal yang paling diminati. Penelitian ini menggunakan metode analisis kluster serta Analytical Hierarchy Process (AHP). Melalui analisis kluster faktor-faktor yang berpengaruh signifikan untuk meningkatkan kinerja Terminal Kabupaten Kapuas terdiri atas 5 (lima) indikator utama yang dijabarkan menjadi 20 (dua puluh) indikator kinerja kunci serta 10 (sepuluh) kluster dengan susunan hirarki yaitu aksesibilitas, waktu tunggu keberangkatan (headway), ketersediaan sarana dan prasarana terminal, biaya transportasi, kapasitas terminal, keamanan lingkungan terminal, tujuan dan arah perjalanan, ketersediaan jumlah dan jenis armada angkutan, kepadatan arus lalu lintas dan kenyamanan lingkungan terminal. Indikator pengaruh yang memiliki bobot yang siginifikan dalam mempengaruhi kinerja Terminal Kabupaten Kapuas pada kondisi eksisting adalah aksesibilitas dengan bobot 13,5\% dan lokasi terminal dan sub terminal yang paling diminati adalah sub terminal Danumare dengan bobot sebesar 59,4\%. Untuk mengoptimalkan kinerja terminal Kabupaten Kapuas sangat diperlukan adanya peningkatan aksesibilitas menuju ke lokasi terminal, ketepatan jadwal kedatangan maupun keberangkatan angkutan, ketersediaan sarana dan prasarana terminal, biaya transportasi yang bersaing, kapasitas terminal, keamanan lingkungan terminal, tujuan dan arah perjalanan, ketersediaan jumlah dan jenis armada angkutan, kepadatan arus lalu lintas dan kenyamanan lingkungan terminal. Hasil AHP pasca pengoptimalan menunjukan adanya peningkatan bobot dari indikator kinerja yaitu aksesibilitas (31,0\%), waktu tunggu keberangkatan/headway $(11,9 \%)$ dan ketersediaan sarana dan prasarana terminal (9,2\%) serta lokasi terminal dan sub terminal yang paling diminati adalah terminal Kabupaten Kapuas (45,3\%), sub terminal Danumare (29,0\%) dan sub terminal Teratai (25,6\%). Jadi, peningkatan kualitas layanan terminal sesuai dengan indikator kinerja kunci sangat berpengaruh terhadap peningkatan kinerja terminal.
\end{abstract}

Kata kunci: kinerja terminal, indikator kinerja, analisis kluster, analytical hierarchy process.

\section{PENDAHULUAN}

Kabupaten Kapuas merupakan pintu gerbang yang menghubungkan pergerakan penumpang dan/atau barang dari Provinsi Kalimantan Selatan menuju Provinsi Kalimantan Tengah. Hal ini berakibat terhadap tingginya frekuensi lalu lintas transportasi darat yang melintasi atau menuju ke Kabupaten Kapuas. Selain pembangunan jalan, juga telah dilakukan pembangunan terminal diwilayah Kabupaten Kapuas.

Terminal angkutan penumpang merupakan salah satu bagian dari sistem

Correspondence: Andrianto Setiawan

Email: ifnosableng77@gmail.com transportasi, tempat kendaraan umum mengambil dan menurunkan penumpang dari satu moda ke moda transportasi yang lainnya, juga merupakan prasarana angkutan penumpang dan menjadi unsur ruang yang mempunyai peran penting bagi efesiensi kepentingan wilayah. Dari penjelasan tersebut maka dapat disebutkan bahwa terminal berfungsi sebagai penunjang kelancaran mobilisasi orang dan arus barang serta tempat perpaduan intra dan antar moda secara lancar dan tertib. Namun, kinerja terminal yang telah dibangun oleh pemerintah masih belum optimal seperti halnya yang terjadi pada Terminal Kabupaten Kapuas.

Oleh sebab itu, dirasa perlu untuk 
melakukan penelitian guna mengidentifikasi, menyusun hirarki, menganalisa indikator pengaruh yang memiliki bobot yang siginifikan dalam mempengaruhi kinerja terminal serta mengetahui lokasi terminal yang paling diminati. Penelitian ini menggunakan metode analisis kluster serta Analytical Hierarchy Process (AHP).

Melalui analisis kluster faktor-faktor yang berpengaruh signifikan untuk meningkatkan kinerja Terminal Kabupaten Kapuas terdiri atas 5 (lima) indikator utama yang dijabarkan menjadi 20 (dua puluh) indikator kinerja kunci serta 10 (sepuluh) kluster dengan susunan hirarki yaitu aksesibilitas, waktu tunggu keberangkatan (headway), ketersediaan sarana dan prasarana terminal, biaya transportasi, kapasitas terminal, keamanan lingkungan terminal, tujuan dan arah perjalanan, ketersediaan jumlah dan jenis armada angkutan, kepadatan arus lalu lintas dan kenyamanan lingkungan terminal.

\section{METODE PENELITIAN}

Pengumpulan data diarahkan untuk mendapatkan data primer dan data sekunder baik yang bersifat kualitatif maupun kuantitatif. Data primer mencakup layout terminal dan data sarana dan prasarana terminal. Sedangkan data sekunder mencakup:

1. Hasil tinjauan lapangan terhadap kondisi eksisting Terminal Kabupaten Kapuas, lokasi lokasi pool, kantor-kantor administrasi perusahaan angkutan umum, kondisi jalan, kondisi lalu lintas dan persimpangan menuju lokasi Terminal Kabupaten Kapuas.

2. Hasil penggalian pendapat atau informasi para responden yaitu dengan melakukan wawancara langsung tak terstruktur dengan (tanpa kuesioner) dan terstruktur (dengan kuesioner) kepada para pengambil keputusan/kebijakan di lingkungan Pemerintah Kabupaten Kapuas, para pengguna jasa angkutan umum dan para penyedia jasa angkutan umum.

\section{HASIL DAN PEMBAHASAN}

Rencana pengembangan terminal angkutan penumpang untuk Kapuas adalah sebagai berikut:

a. Terminal penumpang Tipe B menuju Tipe A yang berlokasi di Kuala Kapuas (PKW)

b. Terminal Tipe $\mathrm{C}$ di Mantangai, Timpah, Pujon, Sei Hanyo, Mandomai, Lamunti, Dadahup, Palingkau, Sei Tatas, Catur dan Lupak.

Kota Kuala Kapuas memiliki Terminal Kabupaten dan 2 (dua) sub terminal yang melayani transportasi darat dengan karakteristik seperti terlihat pada Tabel 1.

Jumlah indikator yang dianalisis adalah 20 (dua puluh) indikator, selanjutnya indikatorindikator tersebut dikelompokan menjadi beberapa kluster. Berdasarkan hasil analisis kluster, diperoleh 10 (sepuluh) kluster yang berpengaruh signifikan terhadap kinerja pelayanan terminal. Adapun hasil analisis kluster dapat dilihat pada Tabel 2.

Tabel 1. Perbandingan Karakteristik Terminal dan Sub Terminal Kabupaten Kapuas

\begin{tabular}{llccc}
\hline \multirow{2}{*}{ No. } & Karakteristik & \multicolumn{3}{c}{ Terminal \& Sub Terminal diwilayah kota Kuala Kapuas } \\
\cline { 3 - 5 } & & Danumare & Teratai & Banama \\
\hline 1. & Kondisi fisik jalan & $\begin{array}{c}\text { Fungsional dan } \\
\text { mantap }\end{array}$ & $\begin{array}{c}\text { Fungsional dan } \\
\text { mantap }\end{array}$ & Rusak ringan \\
2. & Kepadatan arus lalu lintas & Padat & Padat & Lancar \\
3. & Aksesibilitas & Mudah & Mudah & Sulit \\
\hline & & & & (dilanjutkan)
\end{tabular}


Tabel 1 (lanjutan)

\begin{tabular}{|c|c|c|c|c|}
\hline \multirow{2}{*}{ No. } & \multirow{2}{*}{ Karakteristik } & \multicolumn{3}{|c|}{ Terminal \& Sub Terminal diwilayah kota Kuala Kapuas } \\
\hline & & Danumare & Teratai & Banama \\
\hline 4. & $\begin{array}{l}\text { Lokasi (Pasar, Dalam } \\
\text { Kota atau Jalan Lingkar) }\end{array}$ & Pasar & Dalam Kota & Jalan Lingkar \\
\hline 5. & $\begin{array}{l}\text { Tata Ruang } \\
\text { (Pengembangan Wilayah } \\
\text { Kota) }\end{array}$ & Padat & Padat & Tidak Padat \\
\hline 6. & Tujuan Perjalanan & $\begin{array}{l}\text { Desa dan Antar } \\
\text { Kabupaten }\end{array}$ & $\begin{array}{l}\text { Desa dan Antar } \\
\text { Kabupaten }\end{array}$ & $\begin{array}{l}\text { Antar Provinsi, } \\
\text { Antar Kabupaten } \\
\text { dan Desa }\end{array}$ \\
\hline 7. & Jarak dari Pusat Kota & $0,18 \mathrm{~km}$ & $1,1 \mathrm{~km}$ & $5,4 \mathrm{~km}$ \\
\hline 8. & Waktu Tempuh & 5 menit & 10 menit & 30 menit \\
\hline 9. & $\begin{array}{l}\text { Tambahan Biaya } \\
\text { Transportasi }\end{array}$ & - & Rp. $10.000,00$ & Rp. $20.000,00$ \\
\hline 10. & $\begin{array}{l}\text { Jumlah Armada Angkutan } \\
\text { / Taksi }\end{array}$ & 5 Unit & 10 Unit & 20 Unit \\
\hline 11. & $\begin{array}{l}\text { Jenis Armada Angkutan / } \\
\text { Taksi }\end{array}$ & $\begin{array}{l}\text { Minibus dan } \\
\text { Mobil Penumpang }\end{array}$ & $\begin{array}{c}\text { Minibus dan } \\
\text { Mobil Penumpang }\end{array}$ & $\begin{array}{l}\text { Minibus, Mobil } \\
\text { Penumpang } \\
\text { dan Bus }\end{array}$ \\
\hline 12. & $\begin{array}{l}\text { Manajemen } \\
\text { Penyelenggaraan } \\
\text { Terminal }\end{array}$ & Kurang & Kurang & Cukup Baik \\
\hline 13. & $\begin{array}{l}\text { Sarana dan Prasarana / } \\
\text { Fasilitas }\end{array}$ & Kurang & Kurang & Cukup Baik \\
\hline 14. & Kapasitas Terminal & $8 \times 20 \mathrm{~m}^{2}$ & $10 \times 40 \mathrm{~m}^{2}$ & $30 \times 50 \mathrm{~m}^{2}$ \\
\hline 15. & Waktu Tunggu / Headway & 30 menit & 30 menit & 60 menit \\
\hline 16. & $\begin{array}{l}\text { Jumlah/Frekuensi } \\
\text { Perjalanan }\end{array}$ & 10 & 10 & 5 \\
\hline 17. & Tipe Terminal & $\mathrm{C}$ & $\mathrm{C}$ & $\mathrm{B}$ \\
\hline 18. & Konfigurasi Lahan Parkir & Sempit & Sempit & Luas \\
\hline 19. & Kenyamanan Lingkungan & Kurang & Kurang & Cukup \\
\hline 20. & Keamanan Lingkungan & Cukup & Cukup & Kurang \\
\hline
\end{tabular}


Tabel 2. Hasil Analisis Kluster

\begin{tabular}{|c|c|c|}
\hline \multicolumn{3}{|c|}{ Cluster Membership } \\
\hline No & Case & Cluster \\
\hline 1 & Kondisi Fisik Jalan & 1 \\
\hline 2 & Kepadatan Arus Lalu Lintas & 2 \\
\hline 3 & Aksesibilitas & 3 \\
\hline 4 & Lokasi Terminal & 4 \\
\hline 5 & Tata Ruang Pengembangan Kota & 5 \\
\hline 6 & Tujuan Arah Perjalanan & 6 \\
\hline 7 & Jarak Dari Pusat Kota & 7 \\
\hline 8 & Waktu Tempuh dari Pusat Kota & 7 \\
\hline 9 & Biaya Transportasi & 5 \\
\hline 10 & Jumlah Armada Angkutan & 8 \\
\hline 11 & Jenis Armada Angkutan & 8 \\
\hline 12 & Manajemen Pengelolaan Terminal & 7 \\
\hline 13 & $\begin{array}{l}\text { Ketersediaan Sarana dan Prasarana } \\
\text { Terminal }\end{array}$ & 3 \\
\hline 14 & Kapasitas Terminal & 9 \\
\hline 15 & $\begin{array}{l}\text { Waktu Tunggu } \\
\text { Keberangkatan/Headway }\end{array}$ & 10 \\
\hline 16 & Frekuensi/Jumlah Perjalanan & 3 \\
\hline 17 & Tipe Terminal & 4 \\
\hline 18 & Konfigurasi Parkir & 4 \\
\hline 19 & Kenyamanan Lingkungan Terminal & 10 \\
\hline 20 & Keamanan Lingkungan Terminal & 10 \\
\hline
\end{tabular}

Berdasarkan hasil identifikasi terhadap faktor-faktor yang berpengaruh terhadap pengoptimalan kinerja terminal Kabupaten Kapuas ditinjau dari sudut pandang stakeholder (regulator, operator dan user) dengan jumlah 300 (tiga ratus) responden adalah:

a. Tingkat Layanan Jalan (LOS)

b. Aksesibilitas

c. Fasilitas dan Manajemen Terminal

d. Kenyamanan Lingkungan Terminal

e. Keamanan Lingkungan Terminal

Analisis kluster dilakukan dengan menggunakan program SPSS Versi 21. Hasil analisis kluster terhadap jumlah responden yang disampel 300 responden dikelompokan kedalam 10 (sepuluh) kluster. Berdasarkan hasil analisis AHP dapat diketahui bahwa susunan hirarki dari faktor-faktor yang berpengaruh terhadap peng-optimalan kinerja terminal Kabupaten Kapuas eksisting adalah aksesibilitas, ketersediaan sarana dan prasarana terminal, waktu tunggu keberangkatan (headway), keamanan lingkungan terminal, ketersediaan jumlah dan jenis armada angkutan, tujuan dan arah perjalanan, biaya transportasi, kapasitas terminal, kenyamanan lingkungan terminal dan kepadatan arus lalu lintas. Faktor yang paling signifikan dalam mempengaruhi peng-optimalan kinerja terminal ternyata adalah aksesibilitas dengan bobot 13,4\%.

Berdasarkan hasil AHP untuk mengidentifikasi susunan hirarki dan pembobotan kriteria lokasi terminal maupun sub terminal eksisting yang paling diminati oleh Stakeholders adalah:

1. Sub terminal Danumare $(59,4 \%)$,

2. Sub terminal Teratai $(24,9 \%)$, dan

3. Terminal Kabupaten Kapuas (Banama) $(15,7 \%)$.

Hasil identifikasi susunan hirarki dari lokasi terminal yang paling diminati ini menunjukkan bahwa untuk melaksanakan pengoptimalan kinerja layanan terminal Kabupaten Kapuas ada beberapa hal terkait aksesibilitas yang harus dibenahi diantaranya adalah:

1. Penambahan armada taksi/angkutan kota (feeder) dari sub terminal ke terminal kabupaten maupun antar moda transportasi sungai ke transportasi darat.

2. Ketepatan waktu jadwal keberangkatan maupun kedatangan angkutan umum.

3. Peningkatan sarana dan prasarana yang dimiliki oleh terminal Kabupaten Kapuas.

4. Meningkatkan pengamanan di sekitar lokasi terminal Kabupaten Kapuas demi memberikan jaminan keamanan bagi aktivitas di lingkungan terminal.

5. Pembangunan kawasan "core activity" didekat lingkungan terminal sebagai bangkitan arus transportasi.

6. Penertiban trayek angkutan umum dan perijinan angkutan guna mengurangi aktivitas angkutan taksi-taksi liar.

Selanjutnya dengan pendekatan tersebut kembali diadakan survei untuk mengidentifikasi peningkatan kinerja terminal dan sub terminal Kabupaten Kapuas. Perbandingan peringkat masing-masing 
kriteria pada kondisi eksisting terhadap pasca pengoptimalan dapat dilihat pada Tabel 3 . Hasil AHP pasca pengoptimalan dapat diketahui bahwa kriteria yang berpengaruh signifikan terhadap kinerja terminal Kabupaten Kapuas sesuai peringkat diantaranya yaitu aksesibilitas (30,99\%), waktu tunggu keberangkatan/headway $(11,92 \%)$ dan ketersedian sarana dan prasarana terminal $(9,21 \%)$.
Untuk lokasi terminal dan sub terminal yang paling diminati adalah terminal Kabupaten Kapuas (45,3\%), sub terminal Danumare $(29,03 \%)$ dan sub terminal Teratai $(25,65 \%)$. Perbandingan lengkap peringkat kriteria lokasi terminal antara kondisi eksisting dan pasca pengoptimalan dapat dilihat pada Tabel 4.

Tabel 3. Perbandingan Peringkat Masing-Masing Kriteria Pada Kondisi Eksisting Terhadap Pasca Pengoptimalan

\begin{tabular}{|c|c|c|c|c|c|c|}
\hline & \multirow{2}{*}{ Criterion } & \multirow{2}{*}{ Comment } & \multicolumn{2}{|c|}{ Eksisting } & \multicolumn{2}{|c|}{ Pasca Pengoptimalan } \\
\hline & & & Weights & $\mathrm{Rk}$ & Weights & $\mathrm{Rk}$ \\
\hline 1 & Aksesibilitas & $\begin{array}{l}\text { Kemudahan Akses } \\
\text { Menuju Lokasi } \\
\text { Terminal }\end{array}$ & $13,36 \%$ & 1 & $30,99 \%$ & 1 \\
\hline 2 & Tujuan Perjalanan & $\begin{array}{l}\text { Tujuan dan Arah } \\
\text { Perjalanan }\end{array}$ & $8,90 \%$ & 6 & $6,14 \%$ & 7 \\
\hline 3 & Headway & $\begin{array}{l}\text { Waktu Tunggu } \\
\text { Keberangkatan }\end{array}$ & $12,17 \%$ & 3 & $11,92 \%$ & 2 \\
\hline 4 & Sarpras & $\begin{array}{l}\text { Ketersedia-an Sarana } \\
\text { dan Prasarana Terminal }\end{array}$ & $12,80 \%$ & 2 & $9,21 \%$ & 3 \\
\hline 5 & Keamanan & $\begin{array}{l}\text { Keamanan Lingkungan } \\
\text { Terminal }\end{array}$ & $11,59 \%$ & 4 & $7,38 \%$ & 6 \\
\hline 6 & Kenyamanan & $\begin{array}{l}\text { Kenyamanan } \\
\text { Lingkungan Terminal }\end{array}$ & $7,12 \%$ & 9 & $5,10 \%$ & 10 \\
\hline 7 & Arus Lalu Lintas & $\begin{array}{l}\text { Kepadatan Arus Lalu } \\
\text { Lintas }\end{array}$ & $5,90 \%$ & 10 & $5,25 \%$ & 9 \\
\hline 8 & Armada & $\begin{array}{l}\text { Ketersediaan Jumlah } \\
\text { dan Jenis Armada }\end{array}$ & $10,95 \%$ & 5 & $5,92 \%$ & 8 \\
\hline 9 & Kapasitas Terminal & Kapasitas Terminal & $8,31 \%$ & 8 & $9,02 \%$ & 5 \\
\hline 10 & Biaya Transportasi & $\begin{array}{l}\text { Tambahan Biaya } \\
\text { Transportasi }\end{array}$ & $8,90 \%$ & 6 & $9,08 \%$ & 4 \\
\hline
\end{tabular}

Tabel 4. Perbandingan Peringkat Kriteria Lokasi Terminal Antara Kondisi Eksisting dan Pasca Pengoptimalan

\begin{tabular}{clrrrrr}
\hline \multirow{2}{*}{ Criterion } & Comment & \multicolumn{2}{c}{ Eksisting } & & \multicolumn{2}{c}{ Pasca Pengoptimalan } \\
\cline { 3 - 6 } & & & Weights & Rk & Weights & Rk \\
\hline 1 & Danumare & Sub Terminal & $59,36 \%$ & 1 & $29,03 \%$ & 2 \\
2 & Teratai & Sub Terminal & $24,93 \%$ & 2 & $25,65 \%$ & 3 \\
3 & Banama & Terminal & $15,71 \%$ & 3 & $45,33 \%$ & 1 \\
& & Kabupaten & & & & \\
\hline
\end{tabular}




\section{KESIMPULAN}

Berdasarkan hasil analisis terhadap hasil penelitian yang dilakukan dapat disimpulkan beberapa hal sebagai berikut.

1. Faktor-faktor yang berpengaruh signifikan untuk meningkatkan kinerja Terminal Kabupaten Kapuas terdiri atas 5 (lima) indikator utama yang dijabarkan menjadi 20 (dua puluh) indikator kinerja kunci dan 10 (sepuluh) kluster.

2. Indikator pengaruh yang memiliki bobot yang siginifikan dalam mempengaruhi kinerja Terminal Kabupaten Kapuas pada kondisi eksisting adalah aksesibilitas dengan bobot 13,5\% dan lokasi terminal dan sub terminal yang paling diminati adalah sub terminal Danumare dengan bobot sebesar 59,4\%.

3. Untuk mengoptimalkan kinerja terminal Kabupaten Kapuas sangat diperlukan adanya peningkatan aksesibilitas menuju ke lokasi terminal, ketepatan jadwal kedatangan maupun keberangkatan angkutan, ketersediaan sarana dan prasarana terminal, biaya transportasi yang bersaing, kapasitas terminal, keamanan lingkungan terminal, tujuan dan arah perjalanan, ketersediaan jumlah dan jenis armada angkutan, kepadatan arus lalu lintas dan kenyamanan lingkungan terminal.

4. Hasil AHP pasca pengoptimalan menunjukan adanya peningkatan bobot dari indikator kinerja yaitu aksesibilitas (30,99\%), waktu tunggu keberangkatan/headway $\quad(11,92 \%)$ dan ketersediaan sarana dan prasarana terminal $(9,21 \%)$ serta lokasi terminal dan sub terminal yang paling diminati adalah terminal Kabupaten Kapuas (45,33\%), sub terminal Danumare $(29,03 \%)$ dan sub terminal Teratai $(25,65 \%)$.

5. Peningkatan kualitas layanan terminal sesuai dengan indikator kinerja kunci sangat berpengaruh terhadap peningkatan kinerja terminal.

\section{DAFTAR RUJUKAN}

Abubakar, I. 1995. Menuju Tertib Lalu Lintas. Departemen Perhubungan

Direktorat Jenderal Perhubungan Darat. Jakarta.

Anonim. 1992, Undang-Undang No.14 Tahun 1992 tentang Lalu-Lintas dan Angkutan Jalan, Direktorat Jenderal Perhubungan Darat, Departemen Perhubungan Republik Indonesia. Jakarta.

Anonim. 1995. Keputusan Menteri Perhubungan No.31 Tahun 1995 tentang Terminal Transportasi Jalan. Departemen Perhubungan Republik Indonesia Jakarta.

Anonim. 2002. Pedoman Teknis

Penyelenggaraan Angkutan

Penumpang Umum di Wilayah

Perkotaan Dalam Trayek Tetap dan

Teratur. Direktorat Jenderal

Perhubungan Darat Departemen

Perhubungan Republik Indonesia. Jakarta.

Anonim. 2016. Rencana Pembangunan Jangka Menengah Daerah (RPJMD) Tahun 2013 - 2018. Badan Perencanaan Pembangunan Daerah Kabupaten Kapuas.

Gultom .J. 2000. Faktor-Faktor Yang Mempengaruhi Persepsi Masyarakat Terhadap Ketidakefektifan Terminal Induk Natai Suka di Pangkalan Bun Kabupaten Kotawaringin Barat Kalimantan Tengah. Thesis. Fakultas Pasca Sarjana. Teknik Sipil Universitas Gadjah Mada. Yogyakarta.

Hobbs, F.D. 1995. Perencanaan dan Teknik Lalu Lintas. Fakultas Teknik Universitas Gajah Mada, Yogyakarta.

Irjaya, D. et al. 2014. Kajian Dampak Relokasi Terminal Gadang Kota Malang Terhadap Biaya Operasional Kendaraan dan Pengguna Angkutan Kota. Jurnal Civitas Akademik. 
Krishnomo H. 1998. Analisis Performasi Fasilitas Bandar Udara Berdasarkan Kapasitas Eksisting. Thesis, Fakultas Pasca Sarjana Teknik Sipil, Institut Teknologi Bandung.

Mangkusubroto. K. 1987. Pengembangan Metodologi Penjajagan Efektifitas Sistem Usaha Dengan Menggunakan Kriteria Deskriptif Majemuk Dan Berdasarkan Persepsi Pengambilan Keputusan. Disertasi, Institut Teknologi Bandung.

Morlok E.K. 1985. Pengantar Teknik dan Perencanaan Transportasi. Erlangga, Jakarta.

Purba, D. 2008. Analisis Prioritas faktorfaktor yang Mempengaruhi Efektivitas Fungsi Terminal Sarantama (Study Kasus Terminal Sarantama Kota Pematang Siantar). Medan.

Radam, Iphan. F. 2001. Analytical Hierarchy Process. Program Magister Manajemen dan Rekayasa Transportasi. Fakultas Teknis Lambung Mangkurat, Banjarmasin.

Saaty, T.L, 1993. Pengambilan Keputusan Bagi Para Pemimpin, P.T. Pustaka Binaman Pressindo, Jakarta.

Sagi, F.N, et al. 2015. Kajian Faktor-Faktor Penyebab Ketidakefektifan Kinerja Terminal Bus Haumeni Kota Soe Kabupaten Timor Tengah Selatan. Jurnal Teknik Sipil Vol. IV No. 2, September 2015.

Sari, P. M. 2011. Analisis Faktor Penyebab Tidak Optimalnya Terminal Bandar Raya Payung Sekaki di Kota Pekanbaru. Jurnal Planesa Volume 2, Nomor 2 November 2011. Jurusan Teknik Planologi. Universitas Esa Unggul. Jakarta.
Senoadji, B. 2005. Analisis Kinerja Operasional Terminal di Umbulharjo Yogyakarta. Thesis. Fakultas Pasca Sarjana Teknik Sipil Universitas Diponegoro. Semarang.

Silva, N.F.A.D.S et al. 2015. Kajian Kinerja Pelayanan Terminal Angkutan Umum (Studi Kasus Terminal Becora Dili - Timor Leste). Media Teknik Sipil Volume 13 Nomor 1 ISSN 1693-3095.

Sultan, M. A. 2013. Kajian Tingkat Kepuasan Pengguna Infrastruktur Transportasi di Kabupaten Halmahera Utara. Jurnal Sipil SainsVolume 3 Nomor 05 Maret 2013. Fakultas Teknik Universitas Khairun. Halmahera Utara.

Tamin, O.Z, 2000, Perencanaan dan Pemodelan Transportasi. Institut Teknologi Bandung, Bandung.

Ubaidillah, M.T.T, 2013. Studi Evaluasi Kinerja Terminal Mulyorejo Kota Malang. Jurnal Civitas Akademik. Malang.

Utama, D.H. 2000. Analisis Penentuan Prioritas Pengembangan Sumberdaya Air Daerah Aliran Sungai (DAS) Cimanuk Propinsi Jawa Barat Menggunakan Metoda AHP. Thesis. Fakultas Pasca Sarjana Teknik Sipil Institut Teknologi Bandung.http:/www.prodezign.web.id diakses 28 Nopember 2016. 